\title{
From Batch \& Queue to Industry 4.0-Type Manufacturing Systems: A Taxonomy of Alternative Production Models
}

\author{
Bruno G. Rüttimann1, Martin T. Stöckli² \\ ${ }^{1}$ ETH Zürich IWF, Zurich, Switzerland \\ ${ }^{2}$ Inspire AG, Zurich, Switzerland \\ Email: bruno.ruettimann@inspire.ethz.ch, stoeckli@inspire.ethz.ch
}

How to cite this paper: Rüttimann, B. G., \& Stöckli, M. T. (2020). From Batch \& Queue to Industry 4.0-Type Manufacturing Systems: A Taxonomy of Alternative Production Models. Journal of Service Science and Management, 13, 299-316. https://doi.org/10.4236/jssm.2020.132019

Received: March 9, 2020

Accepted: April 17, 2020

Published: April 20, 2020

Copyright ( 2020 by author(s) and Scientific Research Publishing Inc. This work is licensed under the Creative Commons Attribution International License (CC BY 4.0).

http://creativecommons.org/licenses/by/4.0/

\section{(c) (i) Open Access}

\begin{abstract}
For didactic purposes, production models are often segregated into job-shop and flow-shop, a definition that is rather based on cognitive-heuristic logic rather than on Cartesian rigor. This distinction is too simplistic and not suitable to understand the complex functioning of a production system. Based on formalized production theorems and principles, this paper describes the characteristics of the main production models defined by different production-related implementation principles. Such an approach helps to create a systematic overview about the topic leading to taxonomy of the existing manufacturing systems, facilitating the introduction to the topic and a structured learning approach for students. It also allows understanding, comparing, and judging the advantages and disadvantages of present and envisaged new production systems' properties as well as performances in order to select how to transform in the best possible way raw materials into components and finished products. The comparison shows that the envisaged Industry 4.0 production model does not only have advantages, leaving some doubts about the possibility to implement at the same time a maximum flexible and elastic production system while aiming at producing batch size 1 products on demand.
\end{abstract}

\section{Keywords}

Production Theory, Production Laws, Manufacturing Principles, Production Performance, Production Systems, Lean Production, Digitization, Industry 4.0

\section{Introduction}

Production theory is often taught by applying descriptive scholastic methods that are missing a scientific-based Cartesian dimension with related manufac- 
turing laws. In essence, production theory is taught on cognitive-heuristic basis usually combined with simulation algorithms in order to model the complex behavior of dynamic systems. With this paper we intend to structure the topic of production systems classification as well as to give an evaluation of the related performance according to defined production criteria in order to facilitate the introduction to the subject area. Indeed, the teaching scope of production theory usually comprises the following core topics:

1) Description of the different manufacturing processes such as drilling, milling, grinding, rolling, extrusion, casting, etc., as well as new technologies such as additive manufacturing (3D printing), laser ablation, etc., each of the technologies accompanied with the relative processing physics.

2) Methods of work organization such as MTM (Maynard, Stegemerten, \& Schwab, 1948) and shopfloor layout modeling techniques with increased virtual reality 3D-modeling of physical processes

3) Operations research theory for optimal capacity planning such as linear programming based on standard linear optimization algorithms or more sophisticated decisional resolutions techniques (e.g. Hillier \& Lieberman, 2001; Rüttimann, 2015).

4) Queuing theory (e.g. Curry \& Feldman, 2011) for optimal scheduling sequences by applying discrete simulation packages as well as the description of practical applications with MRP2/ERP production planning systems

However, specific production laws, i.e. the "physics of production", usually are not taught, the reason is simple: it has not yet been described. A first attempt to elaborate such "physics" dedicated to production is given in Hopp and Spearman (2000), also reflected in its textbook title Factory Physics, however without being consequent and not hitting the real core of the topic. Production is different from natural science such as mathematics or physics. Indeed, these sciences have been researched and developed during decades to solid governing properties leading to the definition of axioms, theorems, corollaries, and laws. Production, however, lacks a formal theory leading therefore to the above described cognitive-heuristic based knowledge transfer. The very reason for that lies in the nature of the production topic itself. Indeed, production is a complex science because of its multidimensional nature. We can define a production system as (Rüttimann, 2017):

- the optimization of a constraint system within a non-deterministic environment.

- with the objective to transform raw materials into products (physical transformation).

- complying to customer requirements such as OTD (voice of customer).

- having limited process resources available (restricted capacities).

- applying an appropriate allocation, i.e. scheduling of resources (optimal solution).

- by following the economic rationale of minimizing waste of inputs and resources (ROI). 
This definition shows not only how complex it is to manage a production system, but also why a theory model is not easy. Furthermore, at the basis of production there are the four "SPQR" production axioms: speed, punctuality, quality, and return; the economic return has to be an integral part of the equation system (Rüttimann 2017). Every production system, independent of the industry sector, has to comply with these axioms in order to come to a viable and sustainable business model. The challenge to define a comprehensive production-inherent theory was solved for the first time in (Rüttimann, 2017), at least for the physics governing the key performance parameters throughput and lead-time, the two most important properties of a production system. Rüttimann (2017) not only defines several production-specific laws, formalized as theorems, corollaries, and lemmas, but also comprises several production-relevant concepts how a production system works. These concepts have been defined as principles. Indeed, production theory has a twofold characteristic:

- production-specific laws: these laws govern the throughput and lead time of raw material and semi-manufactured components transiting the shopfloor in order to be manufactured and assembled into finished products (governing "physics" model).

- production-related principles: these principles describe alternatives solutions how a production systems is implemented and works; the selection of principles to apply lies in the discretion of the decision maker (applied implementation model).

The production laws are largely derived from basic hydraulics and queuing laws. These laws cannot be influenced, remain invariant, and constitute a kind of not new, but finally formalized production fundamentals. These theorems and corollaries describe the intrinsic properties of a production system. However, with which concepts a production system is implemented, are described by the freely selectable production-related principles. The combination of the applied principles will define the ultimate performance of the production system according to the production laws.

Both parts, the production laws and production principles, are forming the logic of the production system, which corresponds ideally to the "software" how the "hardware" (i.e. the resources) is used. Indeed, a system is composed of several subparts that are not making sense alone. Therefore, the production system can be seen as composed of the following elements:

- the raw materials and products to be produced,

- the manpower and equipment enabling the production, as well as

- the production principles how to produce, and

- the production laws modeling the resulting performance.

Whereas some of the production laws are explained in the next section, some production-related principles are described exemplarily in the following. These principles can be divided into main and secondary principles. The main principles characterizing the production system are:

- production principle. 
- manufacturing principle.

- transfer principle.

We define production principle the way how a product is manufactured, i.e. "make to order" for customized products or "make to stock" for standard off the shelf products. We do not care about the variant "make to engineering" because we are only interested in the physical transformation of raw materials into finished products on the shopfloor level. The manufacturing principle is related to the triggering of production or transfer between different work-centers defined by "push" or "pull" concepts. Comparing analytically the concepts of push and pull, finally leads to the "manufacturing principle identity theorem" defining mathematically a perfect 1-piece flow manufacturing (Rüttimann 2017). Finally, the transfer principle deals with the quantity transferred from one operation or workstation to the other. Principles such as "entire batch" or "single piece", but also intermediate variants like "n-piece" transfer principle, rather determined by the physical handling bin, are also possible. The secondary principles describe further implementation concepts and are e.g.

- scheduling principle (e.g. FIFO, LIFO, earliest due date, shortest processing time).

- debottlenecking principle (e.g. spreading, sequentialization, parallelization).

- queuing principle (e.g. common queue, specific queue).

- allocating principle (1-to-1, 1-to-m, k-to-1, k-to-m).

- balancing principles (fixed zone, dynamic zone, circuit, static).

- storing principle (e.g. random, affinity, frequent use).

- etc.

In our analysis we will enlarge the simplistic segregation of production systems into job-shop and flow-shop, characterizing the production systems according to the combination of main principles shown in Figure 1. We distinguish the classic traditional batch and queue (B \& Q) manufacturing, Ford's flow manufacturing for mass production on transfer-lines (TFL), Toyota's flow-type for Lean just-in-time (JIT) cellular manufacturing, and Industry 4.0 type cyber physical production systems (CPPS).

Combining the manufacturing and the transfer principles we get the theoretically possible main manufacturing modi operandi matrix defining e.g. "single piece pull" mode or "batch push" mode (Rüttimann 2017). It is not the aim of this paper to explain in depth these principles of production theory. The aim is to focus the attention on the fact that derived from this explicit-formalized theory, production can be logically described resulting in a taxonomy of different production systems.

\begin{tabular}{|l|c|c|c|c|}
\hline PRINCIPLE & Trad. B\&Q & TFL Massprod. & Lean JIT & Graph CPPS \\
\hline Production $p$. & m. to order/stock & m. to order/stock & make to stock & make to order \\
\hline Manufacture $p$. & push & push & pull & push \\
\hline Transfer $p$. & batch & 1 -piece & $1 / n$-piece & tbd \\
\hline
\end{tabular}

Figure 1. Taxonomy of production systems defined by the main principles. 
Remarks:

Inspire AG is the leading Swiss competence centre for technology transfer to the mechanical, electrical and metal (MEM) industries and is funded by the Swiss Confederation. It conducts research for the industry, develops state-of-the-art technologies, methods and processes and solves problems in all areas of product innovation and production technology. The affiliated inspire academy is aiming at updating industry managers on production theory and related topics.

With this paper the authors show that it is possible to give a Cartesian theory dimension to production theory and define taxonomy of production systems. They also intend to take action against the lack of appropriate didactic learning material using new insight in order to support the learning process of students.

\section{Some Basic Production Laws}

At first, we have to correct certain misconceptions: in fact, the performance frame of a production system is not freely conceivable because the variables of the performance system show multi-collinearity and are not independent. The performance is therefore a resulting consequence being part of an interdependent system of different variables, as we will see. In mathematics, the performance optimization of a production system belongs to the category of multivariate analysis. It can be compared to a multi-objective function to be maximized where the target functions themselves are interdependent. This leads to the important concept of Pareto optimality, or Pareto efficiency of a system.

If we take $100 \%$ quality and zero equipment failure for granted, a production system with good performance is assumed to have:

- high speed, i.e. short process lead time (PLT).

- high throughput, i.e. high exit rate (ER) given by the capacity (i.e. cycle time) at the bottleneck.

- high flexibility, i.e. low cost sensitivity to mix change (type and variability of product).

- high elasticity, i.e. low cost sensitivity to load change (batch size and volume).

Nevertheless, according to the SPQR axioms, one of the ultimate goals of a production system is the on-time-delivery (OTD) to satisfy the "voice of the customer" (VOC). OTD, PLT, and ER are given by mathematical production laws whereas flexibility and elasticity are given by technological solutions and investment in equipment.

The most important element within a production system is not the most expensive equipment, as often wrongly believed, but the bottleneck equipment, because it limits the throughput of the system. The bottleneck is characterized by its cycle time $\left(\mathrm{CT}_{\mathrm{b}}\right)$ which defines the ER of the whole process. The bottleneck is defined as follows (Rüttimann 2017)

Theorem of Throughput (or Bottleneck Theorem):

Given is a sequence of production steps with each process step having a deterministic but different cycle time CT. The maximum throughput, i.e. the 
maximum exit rate ER, of a process is given by the slowest process step, i.e. the process step with the longest cycle time CT; this process step is called bottleneck.

We can express this theorem with a formal mathematical statement summarized in Equation (1)

$$
\left\{\begin{array}{l}
\mathrm{CT}_{b}=\sup \left\{\mathrm{CT}_{i}\right\} \\
\mathrm{ER}=\mathrm{ER}_{b}=\frac{1}{\mathrm{CT}_{b}}
\end{array}\right.
$$

Another important variable determining PLT performance of a production system is the work in process (WIP). The applied transfer principle (batch or single piece) and the manufacturing principle (push or pull) as well as time traps are defining the quantity and spreading of WIP across the process. WIP formation is defined by the following theorem (Rüttimann 2017).

Theorem of WIP (or Delay Theorem or Time-trap Theorem):

Given is a sequence of production steps with each process step having a different cycle time CT. Each process step with a longer CT than its preceding step is introducing a delay with the consequence of an increasing WIP formation in front of this process step.

Such a process step is called time trap; therefore, a process may have more than one time trap.

We can express this theorem by the following mathematical tautological equation system (Equation (2))

$$
\left\{\begin{array}{l}
\mathrm{WIP}=\sum_{i} \mathrm{WIP}_{i} \\
\frac{\partial \mathrm{WIP}}{\partial t}>0: \mathrm{CT}_{i}>\mathrm{CT}_{i-1} \\
\frac{\partial \mathrm{WIP}}{\partial t}=E[\mathrm{IR}]-E[\mathrm{ER}] \approx \frac{1}{\mathrm{TT}}-\frac{1}{\mathrm{CT}_{b}}
\end{array}\right.
$$

It shows that if the input rate (IR) increases while the ER remains constant, the process will generate a WIP (black box view) and if the cycle times of the different workstations are highly unbalanced, WIP will be the consequence between the workstations (white box view). The equation system (Equation (2)) is therefore topologically closed. According to Little's law (Equation (3)), WIP determines PLT

$$
\mathrm{PLT} \approx \frac{\mathrm{WIP}(t)}{\mathrm{ER}}=\mathrm{WIP}(t) \cdot \mathrm{CT}_{b}
$$

This equation is valid for a single machine (or a work station), but it is generally used by non-experts in an indiscriminant way also for a generic process. The correct equation for PLT regarding a process is

$$
\mathrm{PLT}=\sum_{i=1}^{n} \mathrm{CT}_{i}+\sum_{i=1}^{b} \mathrm{WIP}_{i} \cdot \mathrm{CT}_{b}
$$

where $n>b$; if $n=b$ then Little's law applies also for a multi-step process. These 
are the basic production equations determining performance of a production system. OTD for a perfectly takted production system (ideally $\mathrm{SD}[\mathrm{TR}]=0$ ) is given by the following equation system

$$
\left\{\begin{array}{l}
\forall i: \inf \left\{\mathrm{ER}_{i}\right\} \geq \mathrm{TR} \\
Z: \mathrm{PLT}_{Z} \leq \mathrm{EDT}
\end{array}\right.
$$

Both conditions have to be satisfied simultaneously to observe OTD. However, most production systems are not TR-governed, but have a variable order entry rate $(\mathrm{OR})$ with $\mathrm{SD}[\mathrm{OR}]>0$ where $\mathrm{SD}$ means standard deviation. For this general situation, the following theorem can be enounced (Rüttimann 2017).

Theorem of General Production Requirements (or OTD Theorem):

The necessary and sufficient conditions to supply a customer with OTD, i.e. with the right quantity at the right time, is that first the capacity requirement and second the lead time requirement have to be satisfied simultaneously, independent of the applied transfer principle, i.e. SPF or B \& Q. The capacity requirement is given by the Corollary of Weak WIP Stationarity and the lead time requirement necessitates that MLT plus BWT is shorter than EDT.

Which is translated to the following equation system

$$
\begin{aligned}
& \text { for : } \mathrm{SD}[\mathrm{OR}]>0 \\
& \left\{\begin{array}{l}
\forall i: \inf \left\{\mathrm{ER}_{i}\right\}>E[\mathrm{OR}] \\
Z: \mathrm{BWT}_{Z}+\mathrm{PLT}_{Z} \leq \mathrm{EDT}
\end{array}\right.
\end{aligned}
$$

where BWT means backlog waiting time and EDT means expected delivery time. Please note, instead of PLT, which indicates the time-span one single piece needs to transit the process, it would be more appropriate to talk about MLT (Manufacturing Lead Time). MLT comprises the lead time to produce the entire batch B(n), i.e. from when the first piece enters the process until the last piece of the batch leaves the process (Rüttimann 2017). In Western production systems, with its pronounced batch-culture, the difference between MLT and PLT can be considerably big.

The performance of any production system has to obey to the just above mentioned basic equations. The relationship can be further modeled by the following simplified systemic diagram showing how the variables interact and how they are influencing each other (Figure 2).

It is interesting to notice that high flexibility, which means a diverse production mix (resulting in $\mathrm{SD}\left[\mathrm{CT}_{\mathrm{b}}\right]>0$ ), has a negative effect on the ER and the capacity utilization. High flexibility implies changes of cycle times (CT) at different workstations and creates a dynamically changing bottleneck reducing, according to Equation (1), the production throughput. Unused capacity means a low return on investment (ROI) through higher cost and not exploiting the full potential of the invested capital. Ergo: high flexibility translates in low productivity, which is in fact against industrial logic. To maintain the full capacity at each workstation, however, production necessitates WIP in front of each workstation. A high WIP is the visible result of the dominant Western B \& Q production logic. 


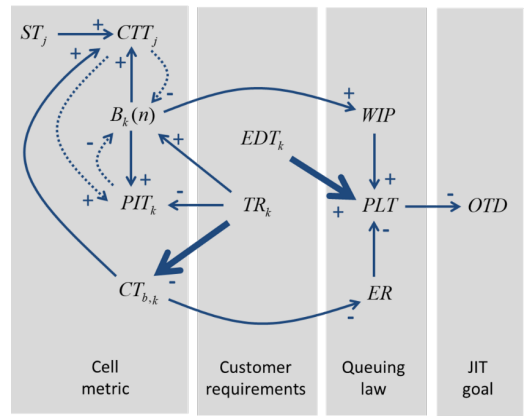

Figure 2. Simplified systemic interactions of production variables (Rüttimann 2017).

This represents a "be-always-busy" logic. The Toyota logic, however, prefers a JIT logic, which represents a "busy-as-necessary" logic to limit overproduction. Overproduction is one of the seven Muda (wastes). Furthermore, yesterday's high value-add per piece paradigm has changed for today's high value-add per hour industry logic, corresponding to a high-productivity of margin generation (Hagen \& Rüttimann, 2004). On the other hand, high elasticity is the desired consequence of investments being able to produce in extremis batch size 1 (Umsetzungsempfehlungen, 2013). But high elasticity also means to be cost-insensitive to load change which forcedly necessitates a variable break-even point (BEP) to be economically viable. Usually, high investments generate high fix-cost increasing $\mathrm{BEP}$, although accompanied by lower specific variable cost. The proposed Industry 4.0 solution (Umsetzungsempfehlungen, 2013) needs huge investment increasing BEP. Here it seems that a contradiction arises (Rüttimann \& Stöckli, 2016).

\section{Classification of Production Systems}

As paraphrased in Figure 1, to transform "input into output", i.e. raw materials into finished goods, different manufacturing systems are available and imaginable, as well as also applied, depending on the type and quantity of the products to be manufactured. In the following, we will give a simplified overview of the main production systems, excluding processing-type ones in the chemical industry. The transformation of inputs into outputs usually means to follow a product-specific production process. This production process usually is the sequence of applying different technologies, such as cutting, drilling, milling, welding, heat treatment, surface treatment, etc., and assembly operations to transform the different components into finished goods.

\subsection{B \& Q Job-Shop Facilities}

Western production systems are typically characterized by a functional department layout, i.e. similar equipment is put physically together. Usually, managers are then talking of machining competence centers, or laser competence centers, etc. Such an equipment layout is typical for a job-shop organized production system where the products of a batch are often transported by lift trucks from one department to the other. This material handling is considered by Toyota to 
be wasted time and therefore a non-value-add activity. However, it has to be said that the presence of many competence centers reveal also the technological know-how mastered and available for the work piece transformation possibilities. Therefore, such a production system constitutes rather a technological capability than a productive capacity to manufacture several different products in a more effective than efficient way. Furthermore, Western production managers are governed by the logic of minimizing production cost applying a logic that is derived from economies of scale, reducing the number of set-ups, i.e. change-overs from one product to another (or from one order to the other order), increasing batch size if possible. This reduces the set-up cost per piece, which reflects the Western full-costing logic and transforms non-productive time in potentially available production time, which is value-add time. This traditional way to produce is called batch \& queue ( $\&$ Q). The production batches are pushed on the shopfloor through the different workstations usually controlled by a weekly campaign scheduling, computed by sophisticated MRP2 or ERP ${ }^{1}$ systems according to different available scheduling principles. The pushed production batches forcedly queue in front of the workstations (according to defined queuing principles) and are waiting to be processed. They form the WIP, often misleadingly called operational reserve, to load all the cycle-time (CT) unbalanced machines rendering them busy. This production system follows a batch transfer principle based on push manufacturing principle, which results in a huge WIP and increases PLT, as we have seen in the previous section. These principles are independent from the production principle, i.e. make to stock or make to order. B \& Q is a job-shop type of production (Figure 3). This production system suits to various products showing high design variability, but with rather low to medium sized production lots. It can be applied indifferently to make to stock or make to order production. The changing mix leads to a changing bottleneck with the consequence of changing ER. High elasticity is intrinsic, but results in unused equipment. In the 70ies, the improved computational power led to CAD/CAM integration, also called CIM (Computer Integrated Manufacturing), and flexible manufacturing systems (FMS), wide spread in classic industries

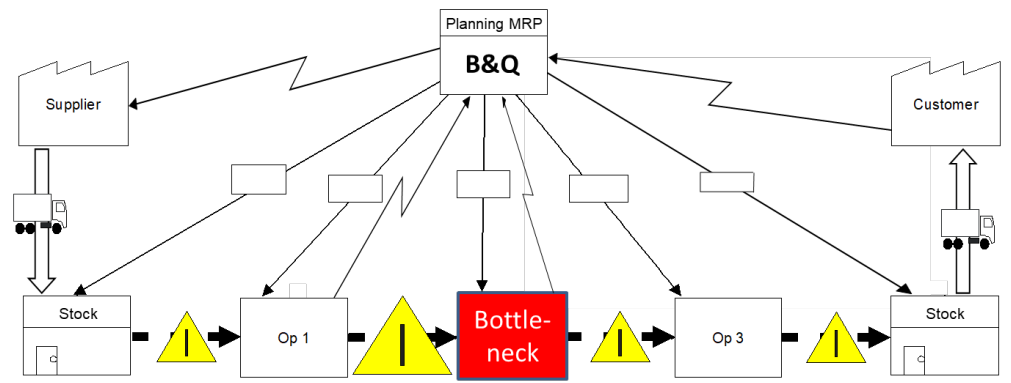

Figure 3. B \& Q push manufacturing system characterized by a high WIP (depicted by I-triangles).

${ }^{1}$ ERP means Enterprise Resource Planning which corresponds to MRP2 (Manufacturing Resource Planning) systems. MRP (or MRP1) means Material Requirement Planning, which was the precursor of today's ERP systems. 
and still at the center of research (e.g. Tolio, Terkaj, \& Valente 2009).

\subsection{TFL Single Piece Flow-Shop Facilities}

To boost production volume, Henry Ford introduced tayloristic-fragmented and CT-balanced assembly lines, which are generally characterized by a push manufacturing principle, following the economies of scale logic. The idea behind is to eliminate the concept of "competence centers" and to put all and only the necessary equipment and workstations or manual assembly operations in a fixed sequence to manufacture the specific product very efficiently. Unlike the batch transfer principle of B \& Q systems, these lines are based on a single piece transfer principle, called single piece flow (SPF) or 1-piece flow, which is the precursor of today's modern automotive transfer lines (TFL). This way to produce increases productivity drastically, reducing also PLT. However, the high productivity was also a dearly bought advantage with decreased flexibility based on the production of only a single product, which was the black-painted Ford T-model becoming the very icon of mass production. With that the term mass-production was born which has reduced production cost drastically; the real era of industrialization had begun. This type of production is also called flow-shop (Figure 4). The technological competence is limited to produce one product, but in high quantity, constituting not a technological, but a productive capability. Such type of production systems suit to standard products with limited variability (entailing limited tool changes and change-overs). Typical non-automotive application examples are high performance bottle filling lines. The ER of such lines is stable and the throughput is influenced only by equipment failures and consequential standstills. Such production systems are capital-intensive and show a high BEP with a low elasticity.

\subsection{JIT Cellular Manufacturing Based on DBR Technique}

Taiichi Ohno of Toyota was impressed by Ford's flow production method, but after WW2 Japan lacked not only natural resources, but had also a different demand characteristic, the market demanded different automotive models. Instead of trying to dominate complexity with MRP systems like in Western manufacturing culture, Toyota tried to eliminate complexity. To increase flexibility while still maintaining the flow concept, he introduced cellular manufacturing. A

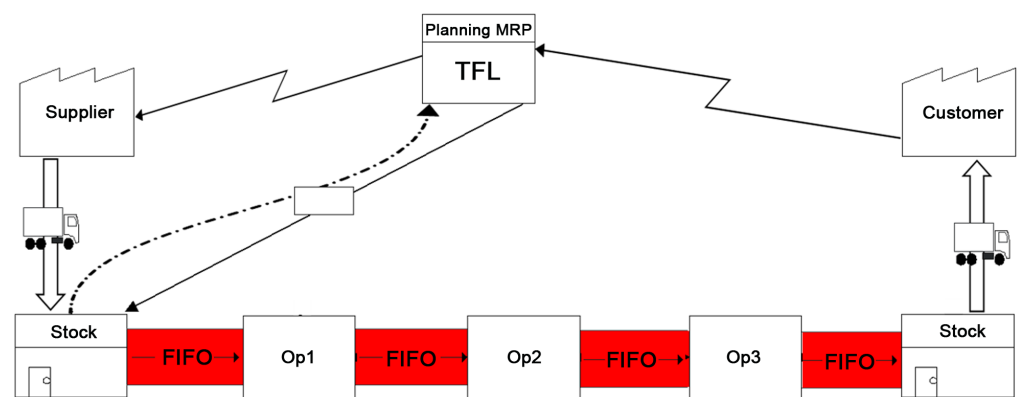

Figure 4. High productivity of a tayloristic-fragmented SPF FIFO TFL with CT-balanced workplaces. 
manufacturing cell gathers the necessary equipment to produce a component in a sequenced line such as in a TFL. Manufacturing cells are a kind of "TFL en miniature" following the economies of scope logic. They are able to produce different similar products within the same cell. This increased flexibility of the original TFL production system. Indeed, the manufacturing cells supply the central backbone assembly line according to non-scheduled, but actual demand-driven withdraws of just buffered components.

To link these different cells, or the TFL, Ohno introduced the American supermarket concept into the shopfloor, which can be regarded as strategic buffers different from WIP. They reduced classic WIP drastically and changed the manufacturing principle from push to pull, i.e. to produce only what is requested, the concept of JIT (Just-in-Time) was born. He called it: beyond large scale production the Toyota production system (TPS) was born (Ohno 1988).

The triggering of production is based on the DBR technique (Drum-Buffer-Rope). The drum (pace maker) is supplied by pulled supermarkets. Different supermarket location principles are possible: shared centralized or decentralized at POU (Point of Use) with different possible storage principles now also served by AGVs (Automated Guided Vehicles). With that Toyota introduced the asynchronous assembly principle. American academics took over this revolutionary concept and divulged it in the 90ies (e.g. Liker 2004).

Ohno continued to develop the TPS, leveling production lots to reduce Mura sustaining the flow concept based on takt rate (TR). TR became the central controlling element of production which resembled to a naturally governed system without waste not needing any MRP2/ERP system because planning and scheduling (and therefore the necessary related principles) have become unnecessary since scheduling was replaced by Heijunka levelling. Allegorically said, JIT was the regulating "invisible hand" of manufacturing according to market demand. By the way, JIT is often wrongly called a synchronous manufacturing system. In reality, or better semantically speaking, it is an asynchronous manufacturing system. Indeed, the supermarkets are separating the manufacturing cells having different CT, CLT (Cell Lead Times), and CTT (Cell Turnover Time). Cells are linked via supermarkets asynchronously, decoupling upstream supply and downstream demand due to the different supply and demand characteristic with different supply and demand rates, but controlled by a unique central governing element, which is the TR. Therefore, the TPS is characterized by multiple internal, and minimally sized, supermarkets representing a replenishment-based make to stock based production. This is the production-theoretic aspect of the TPS. In addition, Ohno introduced the Kaizen approach based on Deming's thoughts of PDCA cycle (Plan, Do, Check, Act), improving continuously the production system by empowering blue-collar workers. In the $80 \mathrm{ies}$, he extended this production system to suppliers and customers, integrating in and outbound logistic: the JPS was born (Japanese Production System).

Today, the TPS/JPS represents the most sophisticated production system, a high performance production system, which has been introduced also in 
non-automotive industries, constituting a real revolution compared to traditional Western manufacturing systems. The benefits are: the right product, with the right quantity, with the requested quality, at the right place at the right time at lowest cost (Figure 5). The TPS has conquered the world of manufacturing under the label of Lean manufacturing (Womack \& Jones, 2003). It works best with products having a deterministic and constant demand, or a limited and time-confined variability, translating into a rather stable takt rate with $\mathrm{SD}[\mathrm{TR}]=0$. Modifying the concept of TR into a generalized order rate (OR), this production systems can be applied in industries other than automotive, adapting the techniques to a variable OR with $\mathrm{SD}[\mathrm{OR}]>0$ following the laws of equation system 6 .

\subsection{Graph-Based CPPS}

According to the i4.0 action group (Umsetzungsempfehlungen, 2013, Zukunftsbild Industrie 4.0 internet) the envisaged Industry 4.0 production system can ideally be interpreted as the interconnection of a network of intelligent workstations with intelligent products and intelligent logistic infrastructure forming a cyber-physical production system (CPPS). Therefore, the morphology of shopfloor layout will resemble to a mix of some flow- and predominant job-shop organized and variably connected flexible work-centers with products queuing in front of workstations. On the shopfloor this CPPS will mainly show a B \& Q principle characteristics to better load these independent, but flexible workstations. This is due to stochastic mix variation in order to reduce down-time of the stand-alone, but graph-organized workstations.

A graph is an abstract mathematic topology consisting of nodes and links representing a network of objects. The graph-based layout of the workstations, or alternatively backbone TFL with off-line customization stations, is enriched by decentralized intelligent entities (workstations, products, vehicles). Whether the postulated decentralized "intelligence/autonomy" is sufficient to optimize the scheduling we leave out here; indeed, a centralized optimization would probably bring better results. In fact, neural-based intelligence is suboptimal compared to centrally-aggregated intelligence controlling the whole system with possible achievement of Pareto efficiency. Furthermore, the idea according to the 44.0 action group is to enable batch size 1 stating literally "to put a Porsche

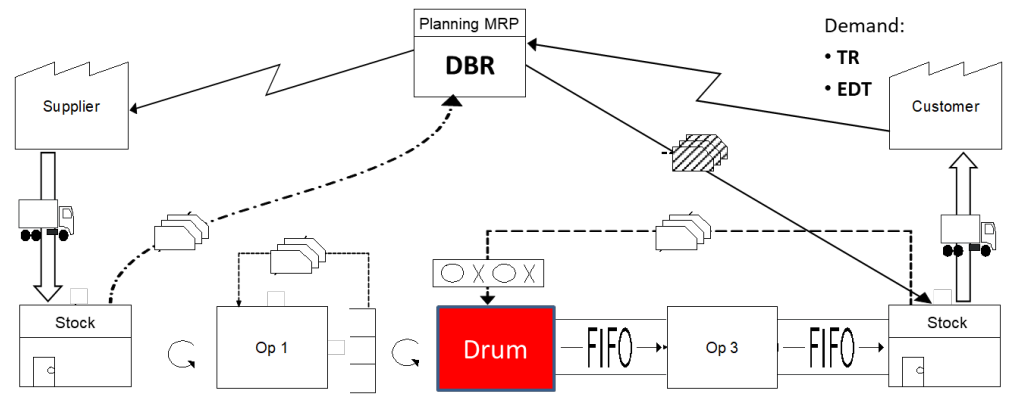

Figure 5. DBR cells with flow on pull SPF characterized by supermarkets to increase flexibility. 
seat into a VW" (Umsetzungsempfehlungen, 2013, Zukunftsbild Industrie 4.0 internet). Whether this makes sense economically, as well as regarding marketing, or even if this is technically desirable is left out as well. The governing algorithm will allow the intelligent products to select autonomously an available and suitable workstation based on the memorized manufacturing sequence projected on the graph, interacting directly with the equipment status (i.e. loaded, scheduled, inactive) of all workstations. Scheduling principles will become important to observe OTD, exploring possible applications with heuristic brute-force method computations. Newly developed RAM-based processing will make it possible (Ielmini, Pedretti, Ambrosi, Bricalli, Wang, \& Sun, 2019) to compute problems of non-polynomial (NP) type of complexity such as exponential or even factorial complexity. Moreover, it allows to communicate via elements of the internet of things (IOT) with the inbound logistics device (arriving lorries), modifying dynamically the production schedule in case of a delay (Figure 6). Although this may sound futuristic and desirable, it will be technically realistic in some years. By the way, Toyota realized these concepts for a restricted deterministic production environment already 30 years ago (JPS). Therefore, Industry 4.0 is not the 4 th revolution in manufacturing. In a broader sense, it represents only the digitization of a JPS-type system. Whether the Industry 4.0 "deus ex machina" system with batch size 1 will be economically viable is left out in this paper. Indeed, high productivity for a production system based on a generalized production model that allows batch size 1 necessitates almost unlimited capacity to allow shortest PLT and observe OTD according to Equations (5) and (6). The explicit aim of the CPPS to produce batch size 1 categorizes it as a make to order production.

If we leave out the benefit of ongoing digitization of production, from which also the other production-type systems will benefit, it is perceivable that this Industry 4.0 manufacturing concept is mainly based on autonomous scheduling of intelligently interacting devices, but still bases on a low performing B \& Q structure if it is not TFL or TPS-based. Let us call this new type of shopfloor manufacturing system "graph-based intelligent CPPS" not yet specifying further the underlying adopted principles until the high-flying dreams of the i4.0 action

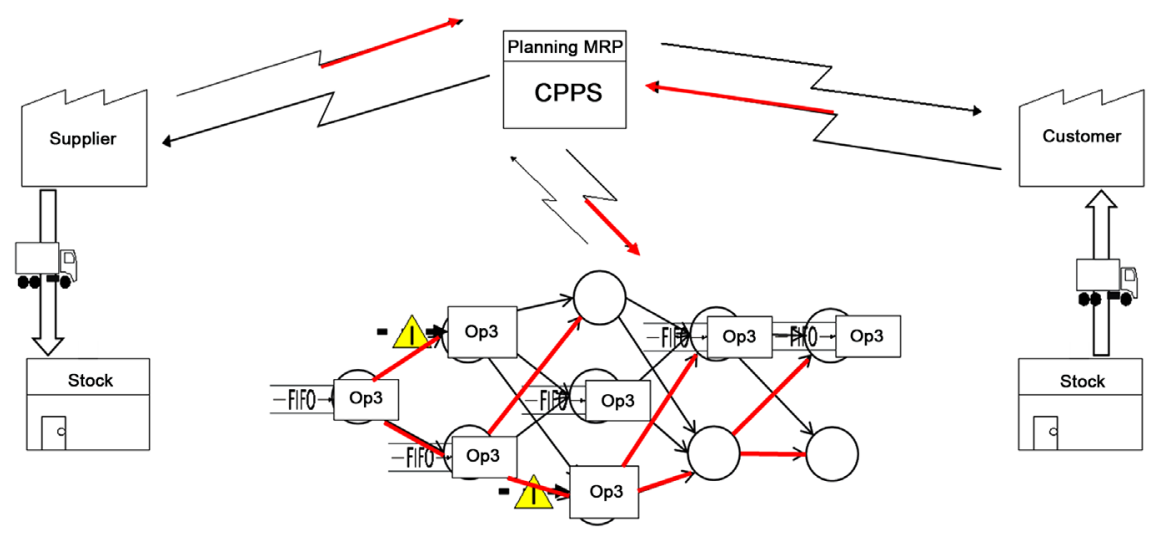

Figure 6. Flexible CPPS based on graph structure with B \& Q allowing batch-size 1 governed by decentralized product/workstation intelligence served by AGVs. 
group will materialize and become clearer. According to the i4.0 action group this system should have maximum flexibility and elasticity.

\section{Gaining Insights and Comparing Performance}

From this short overview it becomes clear that different production systems are existing which are suiting best to a certain product/demand situation. It is perceivable that new and different kinds of production systems are imaginable so a clear attribution to a classic category will become more difficult. Nevertheless, each production system is a mix of different principles, and with the increased digitization they will become also more interconnected, and are offering more opportunities. However, the production laws cannot be by-passed and performance is a consequence of chosen production-related implementation principles, digitized or not. Different than often postulated, the TPS shows a high flexibility, but a deterministic one, while the Industry 4.0 production model tries to implement a stochastic flexibility with the consequence of a dynamically changing bottleneck and all its negative consequences which Toyota named Mura, i.e. unevenness finally leading to Muda, i.e. waste.

The four main production systems are put in Figure 7 in relation to volume and mix. It becomes apparent that the graph-based intelligent CPPS of Industry 4.0 tries to square the circle, where other dedicated production systems suit only high or low volume and high or low mix combinations observing the Pareto frontier, respectively. From Figure 7 it becomes clear that the realistic graph-based CPPS is close to the B \& Q production system and the JIT is rather near to the TFL system. The realistic CPPS has not been put in the upper right corner because it is impossible until now to maximize both characteristics at the same time. Based on this consideration, we can therefore enounce the following postulate.

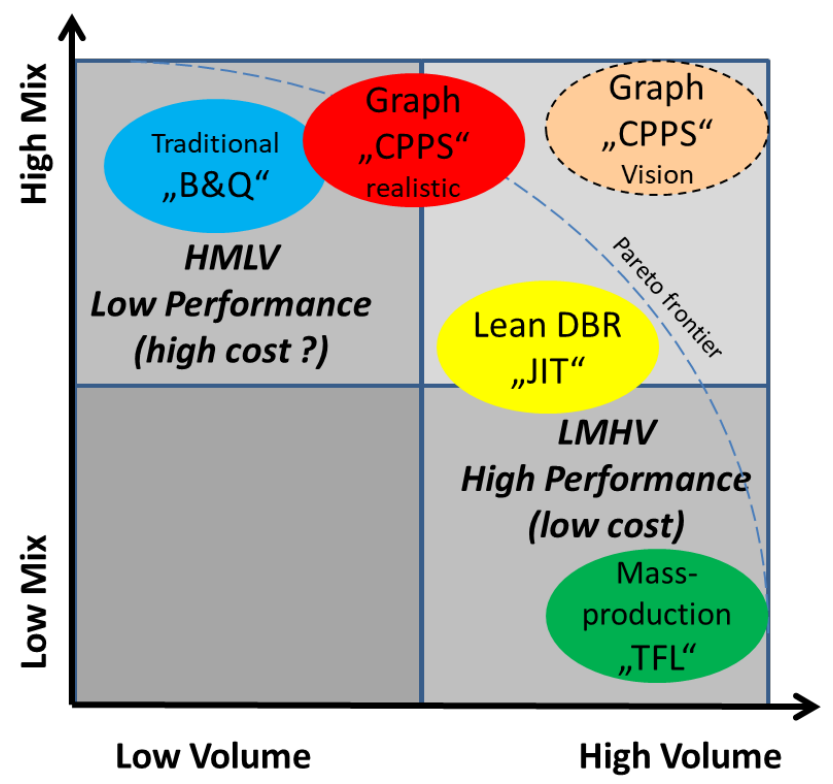

Figure 7. Qualitative volume-mix categorization of main production systems [adapted from Rüttimann \& Stöckli 2016]. 


\section{Postulate of Incompatibility (or Flexibility-Elasticity Postulate)}

$A$ viable production system characterized by a sustainable economic production range beyond the break-even point showing a high operational leverage cannot have at the same time the property of maximum flexibility (i.e. allowing an infinite product mix variability) and the property of maximum elasticity (i.e. allowing an infinite product volume variability).

This postulate bases on the issue addressed under "Some basic production laws" (Section 2) that flexibility reduces the ER and therefore requires a low BEP. This statement, so far, has to be seen as a postulate, because it has not yet been proven. High economic investment given by extended automation, such as fully robotized TFL or artificial intelligence based CPPS of Industry 4.0 type, bear implicitly a low elasticity due to high BEP. Therefore, the postulate of incompatibility is not derived from a technological constraint, which might be solved in the future. The postulate of incompatibility originates from flexibility and the resulting variance of the overall ER, with which the production volume is in jeopardy to fall below the BEP. However, as already stated, digitization can and will be introduced with all production systems. It is important to note: digitization will not change the production system, not to mention the production laws, however, it will change the way how the production system is managed.

If we try to value the performance of these alternative production systems according to the key performance indicators: PLT, ER, flexibility, and elasticity, adding also the cost of investment we arrive at the simplified comparison of Figure 8. Score 5 represents the highest score; investment are best if less intensive. The table shows the supremacy of flow-based systems regarding speed. A time-invariant conceived bottleneck is favorable for flow-based systems resulting in high productivity. We attribute the highest flexibility to CPPS because it is one of the aims of this production system. Already now, it is possible to produce different types of products in flexible gantry-configured robotic cells, so-called Robogate systems, of course only with deterministically defined product variants having a certain demand. Whether a production on demand with a stochastic variability of an unknown product mix can be realized, as the 4.0 action group suggests, has to be proven yet. The imminent SMART FACE project implementation by VW will show. We attribute the highest elasticity to job-shop system and also the investment is the lowest in terms of BEP. Again, high investment, such as Industry 4.0 requires, results in a high $\mathrm{BEP}$, which forcedly reduces

\begin{tabular}{|l|c|c|c|c|}
\hline & Trad. B\&Q & TFL Massprod & Lean JIT & Graph CPPS \\
\hline Speed & 1 & 5 & 4 & 3 \\
\hline Throughput & 3 & 5 & 5 & 4 \\
\hline Flexibility & 4 & 1 & 3 & $5 ?$ \\
\hline Elasticity & 5 & 3 & 4 & $2 ?$ \\
\hline $\begin{array}{l}\text { Overall } \\
\text { performance }\end{array}$ & 13 & 14 & 16 & 14 \\
\hline Investment & 4 & 2 & 3 & 1 \\
\hline Total score & 17 & 16 & 19 & 15 \\
\hline
\end{tabular}

Figure 8. Simplified characterization of alternative production systems. 
elasticity (Rüttimann \& Stöckli 2016). The summary reveals that the Lean JIT production system will dominate, combining the benefits of job-shop flexibility and TFL efficiency. High investment with high BEP implies low elasticity which penalizes the CPPS. Such systems have to be well conceived. Rather than trying to implement an omnipotent system, a well thought-out and confined optimal application range has to be envisaged. However, it has to be stated that also the other production systems have to invest in digital technologies so that the overall performance score represents the reality better.

Nevertheless, there are profound differences in the performance of these systems (HVLM of Ford's unflexible TFL versus LVHM of traditional B \& Q). The highest performance among the existing production systems shows the flow on pull-based TPS. Please note, the surprising low score of graph-based CPPS is not linked to the digitization, it is due to the intrinsic aim of high flexibility reaching batch size 1 necessitating very high investment. But why are not all production managers applying the TPS? Frankly speaking, the reason seems to be sheer ignorance of the management with regard to production knowledge. This lack of knowledge is also a clear failure of universities. Nowadays it is no longer appropriate to ignore the benefits of a Lean production system and what Lean really is - and how it works as well as to what to pay attention - to increase performance of a production system. Unfortunately, many remain stuck to Lean interpreted as waste reduction. Indeed, a more intelligent definition for Lean rather than the widespread notion of a waste reduction tool-set is "Lean is a Kaizen-based JIT-production" (Inspire academy, 2018). This definition reflects on the one hand Deming's practical shopfloor-aspect of continuous improvement and on the other hand the theory-aspect of specific pull characteristic of the TPS. Indeed, Toyota not only developed the JIT production system, but brought also the Kaizen approach to perfection. Kaizen means to improve continuously the production system by the own white and blue collar workforce using their daily increased knowledge while doing their job. The question arises now, how artificial intelligence will support or even substitute the continuous improvement approach. To answer this question, specialists knowledgeable in both topics, Lean Kaizen and artificial intelligence, are necessary.

Please note therefore that a 4.0-type production system does not define a new production system, but will base on existing models defined by their principles extending the flexibility further. The increasing digitization will allow new implementations to pursue the target of maximum flexibility and to reduce BEP. The challenge is not primarily a technological-engineering challenge but rather an informatics-mathematical challenge to find new scheduling algorithms to approach a Pareto optimum in the case of a mighty advanced omnipotent system. At the moment, the currently envisaged distributed control that can be called "neural dynamic rescheduling" allows only to attain a Pareto-inferior Bellman-optimality with reduced performance. However, to implement a Pareto-optimal solution based on distributed intelligence requires that all devices feature the complete mapping of the situation of all devices. How an overall op- 
timization target function can be implemented while each device is optimizing its own limited production strategy has to be analyzed.

\section{Summary and Outlook}

We have seen that the way to produce is a consequence of deliberately selected principles. The resulting production systems, based on intrinsic production laws, will show different performances according to the combination of selected principles. Production systems, and their principles, are also chosen based on the characteristics of products and demands in a specific industry. Not every production system suits to all specific product/demand characteristic. Compared to the classic job-shop and flow-shop distinction, a much more important production system-intrinsic distinction is given by the push/pull distinction. Therefore, production systems can be assigned roughly to two main classes characterized by their manufacturing principle:

- Systems based on push-scheduled principle with sophisticated MRP2/ERP governed systems.

- Systems based on demand-pull principles with naturally triggered and governed systems.

This does not mean that certain principles of demand-pull based systems may not be applied in scheduled push systems, e.g. adopting one-piece SPF transfer principles, or that scheduled-push based systems may not also use a selective pull manufacturing principle. Apart from the process technology, the product and the demand, i.e. the order characteristic, have to be well understood in order to implement an efficient and effective production system. Therefore, the know-how about production theory and the functioning of these complex product-transformation systems stands at the basis for a well thought out conception of a high performance production system.

Nevertheless, the transfer of this know-how lies in the competence of universities, which have to assume this role. The increasing digital content of production will also lead to enlarge the scope of basic production theory to be taught in the future. However, it is necessary to start first with the basic theory in order to gain a scientifically, Cartesian-based and structured understanding.

The possibilities revealed by increased digitization and the goals of Industry 4.0-type production systems lead to additional research topics. These research topics involve the enounced Flexibility-Elasticity Postulate, the characteristic of production performance and respect of OTD in highly variable context, new $\mathrm{Pa}$ reto-optimal scheduling algorithms to respect OTD, as well as the issue of high investment increasing BEP, and how the TPS or generally Lean production systems can evolve into artificial intelligence based digital Lean systems.

\section{Conflicts of Interest}

The authors declare no conflicts of interest regarding the publication of this paper. 


\section{References}

Curry, G. L., \& Feldman, R. M. (2011). Manufacturing Systems Modeling and Analysis. Berlin: Springer. https://doi.org/10.1007/978-3-642-16618-1

Hagen, H., \& Rüttimann, B. (2004). The Automotive Market-The New Challenge for the Aluminium Industry. Aluminium, 80, 5.

Hillier, F. S., \& Lieberman, G. J. (2001). Introduction to Operations Research. New York: McGraw-Hill.

Hopp, W., \& Spearman, M. (2000). Factory Physics. International Edition, New York: McGraw-Hill.

Ielmini, D., Pedretti, G., Ambrosi, E., Bricalli, A., Wang, W., \& Sun, Z. (2019). Solving Matrix Equations in one Step with Cross-Point Resistive Arrays. PNAS, 116, 4123-4128. https://doi.org/10.1073/pnas.1815682116

Inspire Academy (2018). Lean Six Sigma OPEX Curriculum, Inspire AG.

Liker (2004). The Toyota Way, 14 Management Principles from the World Greatest Manufacturer. New York: McGraw-Hill.

Maynard, H. B., Stegemerten, G. J., \& Schwab, J. L. (1948). Methods-Time Measurement. New York: McGraw-Hill.

Ohno, T. (1988). Toyota Production System-Beyond Large Scale Production. New York: Productivity Press.

Rüttimann, B. G. (2015). Discourse about Linear Programming and Lean Manufacturing: Two Different Approaches with a Similar Converging Rational. JSSM, 8, 85-91. https://doi.org/10.4236/jssm.2015.81010

Rüttimann, B. G. (2017). Lean Compendium-Introduction to Modern Manufacturing Theory. Berlin: Springer. https://doi.org/10.1007/978-3-319-58601-4

Rüttimann, B. G., \& Stöckli, M. T. (2016). Lean and Industry 4.0-Twins, Partners, or Contenders? A Due Clarification Regarding the Supposed Clash of Two Production Systems. JSSM, 9, 485-900. https://doi.org/10.4236/jssm.2016.96051

Tolio, W., Terkaj, T., \& Valente, A. (2009). Design of Flexible Production Systems: Methodologies and Tools. Berlin: Spinger Verlag. https://doi.org/10.1007/978-3-540-85414-2

Umsetzungsempfehlungen (2013). Für das Zukunftsprojekt Industrie 4.0-Abschlussbericht des Arbeitskreises Industrie 4.0. http://www.plattform-i40.de

Womack, J. P., \& Jones, D. T. (2003). Lean Thinking. New York: Free Press.

Zukunftsbild Industrie 4.0, Internet. http://www.plattform-i40.de 